\title{
Urazole as an unorthodox functional group for fabrication of anionic hydrogels and ion-exchange materials
}

\author{
Saltuk B. Hanay, ${ }^{\text {abc }}$ Ali Fallah, ${ }^{\text {a }}$ Efsun Senturk, ${ }^{\text {ac }}$ Ferdows Afghah, ${ }^{\text {a Hulya Yilmaz }}{ }^{\text {b }}$ Mustafa Culha ${ }^{\text {bd }}$, Bahattin Koc ${ }^{\text {a }}$ \\ In this study, highly ionazable protons (pKa 5-6) of urazole were exploited to obtain an anionic hydrogel in two simple and scalable steps. Commercially \\ available multiisocyanate, poly(hexamethylene)diisocyanate, was used to prepare urazole containing gel. Urazole formation was confirmed by FT-IR and \\ ${ }^{1} \mathrm{H}-\mathrm{NMR}$ spectroscopy. The hydrogel were characterized by microscopy imaging, spectroscopic and gravimetric analysis. Mechanical analysis and cell \\ viability test were performed for its initial biocompatibility evaluation. The prepared hydrogel is a highly porous hydrogel with a Young's modulus of \\ $0.91 \mathrm{MPa}$, has swelling ratio of $87 \%$ and capable of exchanging ions in a medium. In this report, we demonstrated a strategy to overcome synthetic \\ challenge of incorporating urazole into a material via precursor path rather than attempting to embeding urazole groups directly.
}

\section{Introduction}

Hydrogels have become a very important class of materials, with the global sales reaches approximately 15-20 billion U.S. dollars annually. ${ }^{1}$ Since their first demonstrated application in $1960,{ }^{2}$ hydrogels have found uses in many different areas such as contact lenses, wound dressings, cosmetics, drug delivery systems, tissue engineering, agriculture, and hygiene products. ${ }^{3}$ Hydrogels can be made of synthetic polymers such as polyethyleneglycol (PEG), natural polymers such as gelatin and collagen, or hybrids of natural and synthetic polymers. ${ }^{4}$ The choice of polymers and crosslinkers is crucial, as this affects the final properties of the hydrogel. Pore size, mechanical properties, swelling ratio, swelling rate, biodegradability, biocompatibility, chemical resistance, optical properties, and stimuli responsiveness are additional important hydrogel properties, which must be tailored according to the application. For example, a high swelling ratio and fast swelling kinetics are needed for superabsorbent applications. ${ }^{5}$ On the other hand, biodegradability and biocompatibility are more important for drug delivery ${ }^{6}$ or tissue engineering applications. Hydrophilicity is a vital property of all hydrogels, with hydrophilicity generally provided by hydrophilic polymers, such PEG or polyacrylamides. Although there are numerous reports on different types of hydrogels, novel formulations that can outperform commercial products are still needed. New hydrogel formulations with superior properties may not be enough for commercialization, as the scalability of the hydrogel synthesis, availability and cost of the starting materials are also critical factors for industrial production. In this paper, we describe a facile method to fabricate a novel hydrogesl based on urazole starting from cheap and readily available precursors. We also demonstrated the potential of urazole based hydrogels as ion-exchange materials.

Urazoles are nitrogen-containing heterocycles that have been mostly used as precursors of triazolinediones (TADs). TADs have recently attracted attention owing to their click and click-

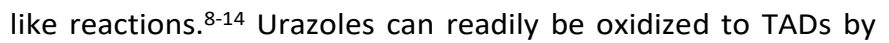
strong oxidants. ${ }^{15-16}$ Alternatively, some urazoles can be aerobically oxidized to corresponding TADs by laccase

enzyme. ${ }^{17}$ Urazole oxidation can also be achieved in situ using a ruthenium photocatalyst. ${ }^{18}$ In general, TAD or in situ oxidized urazole forms adducts that urazoles are bound to a material or a polymer via urazole's amide nitrogen. On the other hand, there are only a few reports that urazole is attached to material via its imide nitrogen. ${ }^{19-20}$ It is important to note that urazole group is untouched when attached via imide nitrogen. However, in these previous two reports, urazole oxidized to TAD and reacted further for other purposes. Therefore, urazole were not utilized as functional group. Urazole has rarely been thought as functional group due to TAD's highly successful click reactions. However, urazole protons are highly ${ }^{21-22}$ acidic and might be exploited to obtain functional materials having anionic character. The acidity of urazole was studied in details as proton-transfer reactions ${ }^{23}$. In one study, the acidity of urazole was exploited to obtain novel polymers via $\mathrm{N}$-alkylation. ${ }^{24}$ Some urazole derivatives, such as 4-oleyl urazole and 1,2 Diacetyl-4oleyl urazole, have been patented as additives for functional fluids. ${ }^{25}$ The potential of urazoles as analogs of prostaglandins in bronchodilation has been demonstrated. ${ }^{26}$ Interestingly, urazole was thought to be a precursor of uracil in the pre-RNA world, as it reacts with ribose to form four different ribosides. ${ }^{27}$ Recently, Yang et. al. used urazole to synthesize urazole-gold nanoparticles to determine curcumine using a fluorescent spectrometer. ${ }^{28}$

Our strategy to obtain a urazole-containing material involves embedding urazole's precursor (semicarbazide) in the polymer backbone rather than attaching urazole directly to a material. The latter strategy is challenging because of the amide protons of urazole. Semicarbazide was cyclized to urazole on the material in a solid state step under strong basic conditions. The resulting urazole-containing gel was a hydrogel, with $87 \%$ swelling ratio and $0.91 \mathrm{mPa}$ elastic modulus. Interestingly, the polymer backbone of the material is highly hydrophobic, with the ionic salt character of urazole conferring hydrophilicity. We also demonstrated that a urazole-salt ionic pair can be exploited as an ion exchanger. When the hydrogel was placed in tap water, it successfully removed $\mathrm{Ca}+2$ and $\mathrm{Mg}+2$ from the water.

\footnotetext{
a) Department of Material Science and Nanoengineering, Sabanci University, Tuzla, 34956, Istanbul, Turkey

b) Sabancı University Nanotechnology Research and Application Center , (SUNUM) ,Tuzla, 34956 Istanbul, Turkey

c) Hanay Ileri Kimya Arastirma Gelistirme ve Muhendislik AS (Hanay Advanced Chemicals Inc.), Kagithane, 34413, Istanbul, Turkey

d) Department of Ophthalmology, Morsani College of Medicine, The University of South Florida, Tampa, FL

*Corresponding author, saltuk.hanay@sabanciuniv.edu
} 


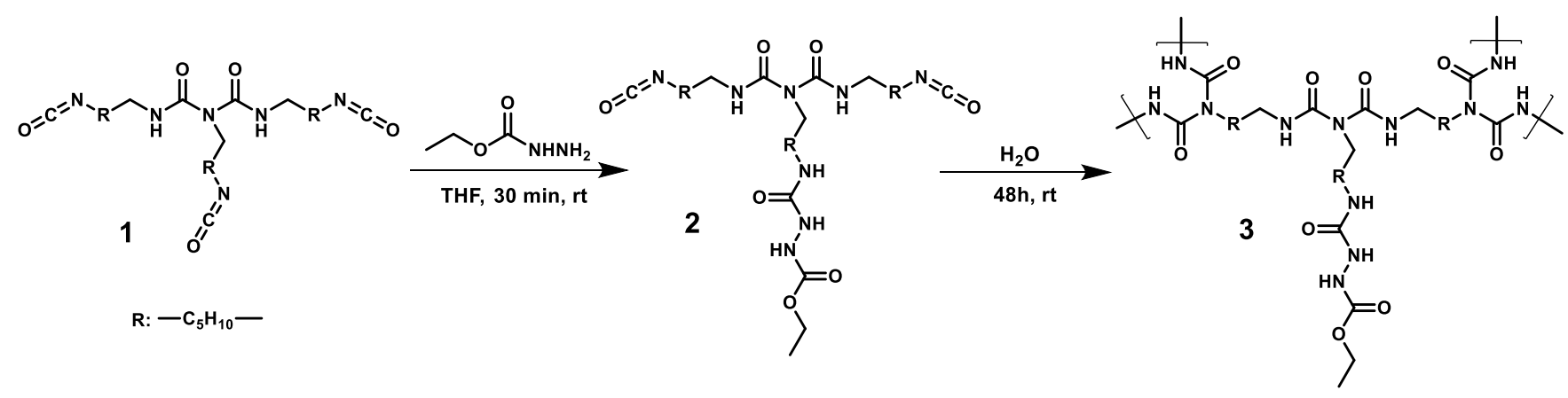

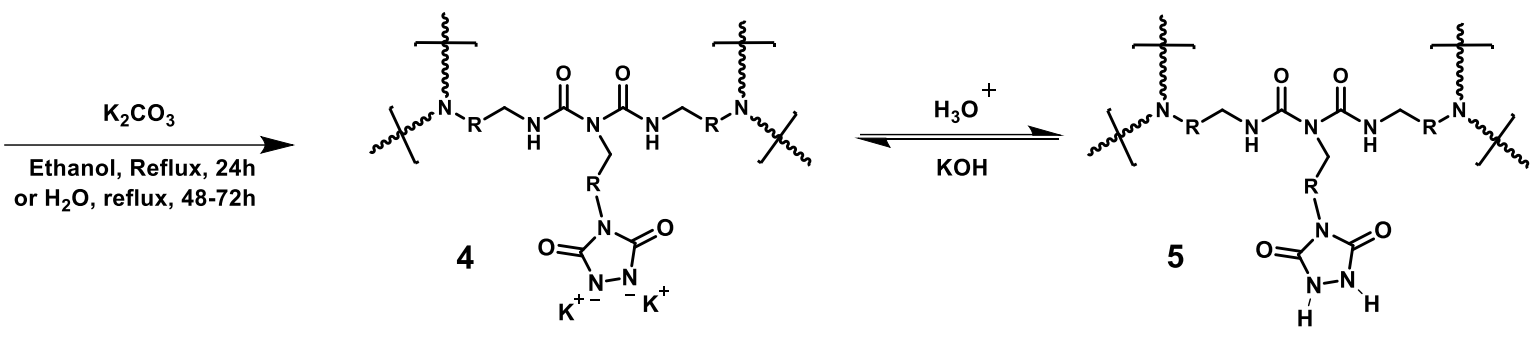

Scheme 1: Synthesis of semicarbazide gel (3), urazole potassium salt hydroge (4) and urazole gel as free acid (5).

Urazole containing material has a potential to be used in real life applications as it has very high Young's modulus, low toxicity profile, and ion responsiveness, this cheap and scalable production method makes this material a promising candidate for hydrogel applications.

\section{Experimental}

\section{Materials and methods}

\section{Materials}

All reagents were purchased from Sigma-Aldrich unless otherwise noted. THF was purchased as anhydrous and inhibitor free (>99.9). Poly(hexamethylene diisocyanate) -viscosity 1,3002,200- was kept under nitrogen after opening the bottle.

\section{Methods}

Nuclear Magnetic Resonance (NMR) was done using a Varian $500 \mathrm{MHz}$ spectrometer at ambient temperature. Attenuated total reflection (ATR) FT-IR spectra were recorded using a Perkin-Elmer Spectrum 100 in the region of $4000-650 \mathrm{~cm}^{-1}$. Four scans were completed with a resolution of $2 \mathrm{~cm}^{-1}$. A background measurement was performed prior to loading the sample onto the ATR for measurement. Raman spectroscopy (Renishaw in Via Reflex Raman Microscope and Spectrometer). Nd-YAG laser with a power of $0.5 \mathrm{~mW}$ at $532 \mathrm{~nm}$ was used for the data acquisition and the spectral range was kept from $300 \mathrm{~cm}^{-1}$ to $3000 \mathrm{~cm}^{-1}$. Thermogravimetric analysis (TGA) was performed (Shimadzu, DTG-60H) from room temperature to $500^{\circ} \mathrm{C}$ with a heating rate of $10^{\circ} \mathrm{C} \mathrm{min}^{-1}$ in a nitrogen atmosphere. Mechanical behaviour of the synthesized gel and hydrogel, a tensile test was performed. The test was performed using the Instron 5982 universal tensile system (Instron) with a $200 \mathrm{~N}$ static load cell and at tension rate of $5.0 \% / \mathrm{min}$ up to failure of the samples under constant temperature and humidity conditions. Material tensile modulus (E) was determined from the linear portion of the stress-strain curve slope. Moreover, ultimate stress and fracture strain is also reported.Ion chromatography analysis were purchased as a service from water analysis laboratories of Istanbul Munipilacity Water and Sewege Administration (ISKI).

Synthesis of semicarbazide gel: In a typical synthesis, $8.6 \mathrm{~mL}$ poly(hexamethylene diisocyanate) was added to an oven dried $100-\mathrm{mL}$ round bottom flask together with $50 \mathrm{~mL}$ anhydrous tetrahydrofuran (THF) under inert conditions. This mixture was stirred for 10 minutes while keeping flask in an ice bath. 2.10gram ethyl carbazate was dissolved in $20 \mathrm{~mL}$ THF and added to the round bottom flask over 3-5 minutes in portions. Then, reaction was kept stirring for 60 more minutes. After, $100 \mu \mathrm{L}$ water added and the solution was poured into glass petri dishes. Then, a watch glass was put over it for 2 days to let THF evaporate slowly. After, the watch glass was removed and all THF was evaporated for 2 more days. Finally, gel was peeled from the petri dish (ESI Figure S1).

Synthesis of urazole gel as potassium salt: In a typical synthesis, 10 grams of semicarbazide gels from previous step were cut into the pieces and placed into $100-\mathrm{mL}$ round bottom flask. In method $\mathrm{A}, 3$ grams of anhydrous $\mathrm{K}_{2} \mathrm{CO}_{3}$ and anhydrous ethanol was put and refluxed for 24 hours. After, gel was placed into beaker and kept in $100 \mathrm{~mL}$ water for 20 minutes. This process repeated for 4 times. Then, gel was dried under open air for 23 days. In method $\mathrm{B}$, gels were placed into aqueous $\mathrm{K}_{2} \mathrm{CO}_{3}$ solution $(10 \% \mathrm{w} / \mathrm{w})$ and refluxed for 2 days. Finally, gels were dialyzed against $\mathrm{DI}$ water several times to remove $\mathrm{K}_{2} \mathrm{CO}_{3}$ completely.

Synthesis of urazole gel as free acid: Potassium salt version of urazole gels were placed into DI water. Then, concentrated $\mathrm{HCl}$ is added until $\mathrm{pH}$ of solution becomes 1 . Gels were kept at this $\mathrm{pH}$ for 4 hours and then dialyzed against $\mathrm{DI}$ water several times to remove $\mathrm{HCl}$ and $\mathrm{KCl}$ completely.

Synthesis of poly(hexamethylene-semicarbazide): In a typical synthesis, $4.3 \mathrm{~mL}$ poly(hexamethylene diisocyanate) was added to semicarbazide solution ( $3.3 \mathrm{gram}$ ) in $100 \mathrm{~mL}$ anhydrous tetrahydrofuran (THF) under inert conditions. This mixture was stirred for 10 minutes while keeping flask in an ice bath. Then ice bath is removed, and reaction kept stirred for an hour at 
ambient temperature. White polymeric sticky material was precipitated in the reaction flask over time. Then- THF decanted and $100 \mathrm{~mL}$ fresh THF was added and stirred for 30 minutes to remove excess semicarbazide. Finally, THF was decanted, and material dried under vacuum. Isolate yield: 7.43 gram $93 \%$.

Synthesis of poly(hexamethylene-urazole): 2 grams of poly(hexamethylene-semicarbazide) were added into oven dried $100 \mathrm{~mL}$ round bottom flask. Then, 1 gram of anhydrous $\mathrm{K}_{2} \mathrm{CO}_{3}$ and $60 \mathrm{~mL}$ anhydrous ethanol were added. Mixture was refluxed for 24 hours. Then, most of the ethanol was decanted carefully and the rest removed under vacuum. Sticky polymer $\mathrm{K}_{2} \mathrm{CO}_{3}$ mixture dissolved in ice-water mixture. Then, $6 \mathrm{M} \mathrm{HCl}$ added slowly, and white solid was precipitated immediately. More $\mathrm{HCl}$ added until $\mathrm{pH}$ of solution became 1-2. Product was collected by vacuum filtration and washed with excess DI water to remove acid. Sticky polymeric material was dissolved in $\mathrm{CHCl}_{3}$ and transferred into vial. Finally, chloroform removed under vacuum. Isolated yield: 1.61 grams.

Synthesis of triazolinedione gel: In a typical synthesis, $200 \mathrm{mg}$ of urazole gel placed into $3 \mathrm{~mL}$ dichloromethane. Then, $100 \mu \mathrm{L}$ $\mathrm{HNO}_{3}$ was added, and mixture was shaken vigorously for 3-5 minutes. Finally, gels were filtered and washed with excess dichloromethane to remove residual $\mathrm{HNO}_{3}$.

Quantification of Urazole Content: $150 \mathrm{mg}$ of 2-naphthol dissolved in $7.5 \mathrm{~mL} \mathrm{CDCl}$. To this solution, one drop of acetonitrile was added to use as integration reference. $1 \mathrm{~mL}$ aliquots of this solution were added onto three batches of the TAD-gel that was oxidized and washed 10 minutes ago. After 45 minutes, $0.7 \mathrm{~mL}$ of these solutions were taken for NMR analysis. 2-naphthol loss was determined by NMR integration after normalizing acetonitrile peaks in each spectrum.

Determination of swelling ratio of hydrogels: Swollen hydrogels were frozen using liquid nitrogen and then freeze dried to complete dryness. Then, freeze dried gels were placed into DI water or phosphate buffer. Masses of wet hydrogel was recorded until it reaches equilibrium. Finallly, swelling ratio was calculated using the formula below.

Swelling ratio $=$ (Mass of wet gel - mass of freeze dried gel)/mass of freeze dried gel $x 100$

Ion-exchange study: $550 \mathrm{~mL}$ of tap water was collected into a $1 \mathrm{~L}$ Erlenmeyer flask. $50 \mathrm{~mL}$ of it was separated and kept as a control group. 50 grams of dry urazole-potassium gels were added to the tap water. After 2,8 and 120 hours, $10 \mathrm{~mL}$ aliquots of water were taken for ion-chromtography analysis. Samples were filtered thorough 0.22 um or 0.45 um filter before analysis Cell Culture. Human skin fibroblast (HSF) cells (ATCC, PCS-201030) were incubated at $37{ }^{\circ} \mathrm{C}$ under in humidified atmosphere air with 5\% CO2 and cultured in Dulbecco's modified Eagle's medium (DMEM, Sigma, Germany) supplemented with 5\% Penicillin-Streptomycin Ampicillin (PSA), 5\% I-glutamine, and $10 \%$ fetal bovine serum (FBS) in tissue culture flasks (TPP, Germany). Cells were harvested Trypsin/D-Hanks solution (0.25 $\mathrm{w} / \mathrm{v} \%, \mathrm{Gibco}$ ) at reach $90 \%$ confluency then seeded at a density of $5 \times 10^{3}$ cells/well in a 96-well plate for incubation $24 \mathrm{~h}$.

Cell Viability Assay

Cell viability analysis was measured using tetrazolium salt WST1 colorimetric assay after treatment of hydrogel extract on seeded cells in a 96-well plate. Autoclaved samples were prepared $0.02 \mathrm{mg}$ based on ISO 10993-12 protocol and incubated in $1 \mathrm{ml} \mathrm{DMEM} 72 \mathrm{~h}$ at $37{ }^{\circ} \mathrm{C}$ at $80 \mathrm{rpm}$. Therefore, seeded cells were cultivated as $100 \%$ and $50 \%$ extract concentration and negative and positive controls contained no material and 5\% DMSO, respectively. After $2 \mathrm{~h}, 6 \mathrm{~h}, 24 \mathrm{~h}, 48 \mathrm{~h}$, and $72 \mathrm{~h}$ incubation, followed by the removed medium from each well was rinsed with PBS to clean the complete extraction residue. The treated cells were cultivated with a medium contained $\% 10$ WST-1 at $3 \mathrm{~h}$. Consequently the formazan was converted from tetrazolium salt in living cells, medium was measured absorbance at $450 \mathrm{~nm}$ with an ELISA reader. The cell viability percentage data calculated with normalized negative control.

\section{Results and Discussion}

The synthesis of the urazole gel is shown in Scheme 1. In the first step, a multifunctional isocyanate, namely (1) poly(hexamethylene diisocyanate), was reacted with the equimolar ethyl carbazate to form an isocyanate semicarbazidecontaining prepolymer intermediate (2). In the same reaction flask, polymerization of this intermediate was initiated via the addition of a small amount of water. The polymerization of poly(urea) was also accompanied with gelation. This process is highly sensitive to moisture and heat. High temperatures or open air conditions results in bubbles in the gel (Electronic Supporting Information: ESI Figure S1). However, bubble free gels can be obtained by carrying the gelation reaction at ambient temperatures and inert conditions.(ESI Figure S2)

The semicarbazide-containing gel (3) was cyclized into a urazole-potassium gel (4) under strong basic conditions at high temperature. Urazole cyclization is efficient and fast when Ethanol $/ \mathrm{K}_{2} \mathrm{CO}_{3}$ is used. However, ethanol-water switch may damage hydrogels. Therefore, at the gel washing step, solvent exchange should be done carefully and slowly to prevent stress on the gels. Although aqueous $\mathrm{K}_{2} \mathrm{CO}_{3}$ cyclization is very slow and less efficient, the gels can be washed easily with water.

Urazole potassium gel can be acidified to obtain a urazole gel in a free acid form (5). Interestingly, a urazole-potassium gel (4) can hold a large amount of water owing to its urazole-potassium salt groups.

The gels synthesized were characterized by FT-IR and Raman spectroscopy. ${ }^{1} \mathrm{H}$-nuclear magnetic resonance (NMR) analysis of urazole cyclization was done using a model compound, as the gels are crosslinked and not soluble. To obtain a soluble model compound, all isocyanates group of poly(hexamethylene diisocyanate) was reacted with ethyl carbazate to form poly(hexamethylene semicarbazide) (ESI, Scheme S1). The model compound is soluble in DMSO, and ${ }^{1} \mathrm{H}-\mathrm{NMR}$ spectrum analysis showed that semicarbazide and urazole formation was successful (Fig. 1). FT-IR spectrum of semicarbizde gel (3) and urazole gel (4) reveals that new carbonyl mode at $1767 \mathrm{~cm}^{-1}$ is appeared after urazole formation when gel is in free acid form (Fig. 2). Additionally, carbonyl mode of semicarbazide at 1724 $\mathrm{cm}^{-1}$ is disappeared. These FT-IR findings are also in agreement with our previously synthesized urazole compounds in which their structures were also confirmed with ${ }^{1} \mathrm{H}-\mathrm{NMR} .{ }^{29}$ Urazole 
potassium salt has a unique mode at $1597 \mathrm{~cm}^{-1}$ and carbonyl mode at $1767 \mathrm{~cm}^{-1}$ is also not present when analysis was done under dry and neat conditions.

Urazole formation was determined qualitatively and quantitively by oxidizing them into triazolinediones (TAD). ${ }^{30}$ TAD formation can be monitored by naked eye owing to distinct $\mathrm{red} / \mathrm{pink}$ color of TAD groups. The oxidation can be with strong oxidants such $\mathrm{HNO}_{3}$ or dibromohyndation in dichloromethane. In some cases, semicarbazide derivatives may form diethylazodicarboxylate (DEAD)-like structures upon oxidation, which have a similar color (orange to red) to TADs and similar reactivity to TADs. When we treated the semicarbazide gels (3) with strong oxidizers, including $\mathrm{HNO}_{3}$ and 1,3-Dibromo-5,5dimethylhydantoin, at least for 1 hour, we observed no color change in the material. This indicated that the red color of the gel was due to the urazole group instead of a possible DEAD like by-product.

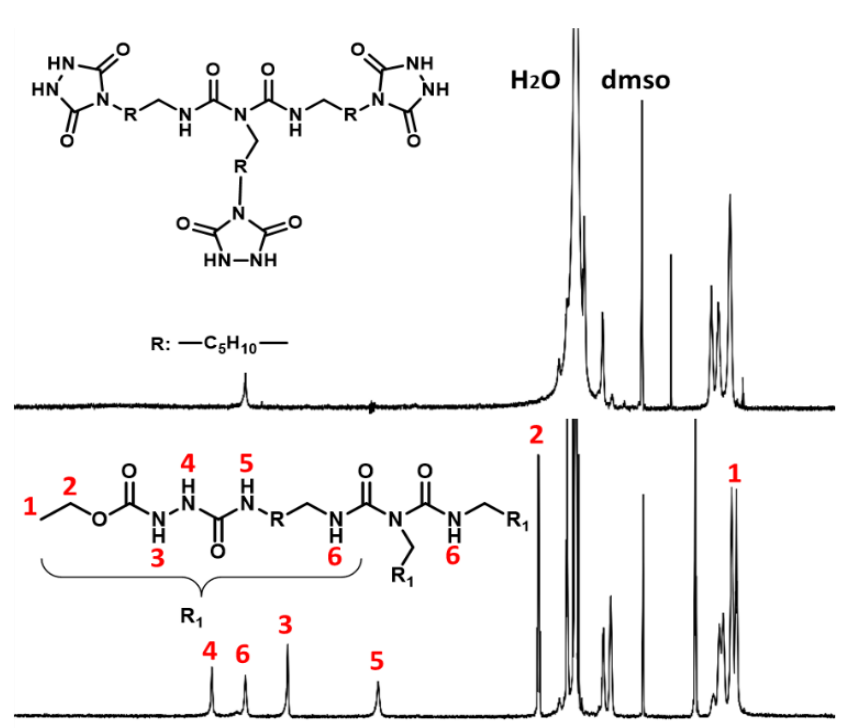

$$
\begin{array}{llllllllllll}
11 & 10 & 9 & 8 & 7 & 6 & 5 & 4 & 3 & 2 & 1 & 0
\end{array}
$$

Figure 1. ${ }^{1} \mathrm{H}-\mathrm{NMR}$ spectrum of the model compounds poly(hexamethyleneurazole) and poly(hexamethylenesemicarbazide).

Quantification of urazole groups can be done by indirectly by determining the TAD groups on the gels. Titrating TAD groups against one of the reactants can be used for quantification. However, the titration method is prone to human error, as reactants take some time to diffuse deep into the gel. NMR analysis is a more reliable method to quantify TADs. A stock solution of a TAD reactive molecule can be reacted with a TAD gel to determine the TAD content of the gel. However, the target molecule should be chosen carefully. For example, furan has a low boiling point $\left(30^{\circ} \mathrm{C}\right)$, and some of it could easily escape causing a positive error in TAD quantification. On the other hand, aniline gives 1:2 adducts with TAD that causes a negative error in quantification (ESI, Figure S3,S4). Additionally, amine group of aniline can also decompose TAD over time that complicated analysis. Similar to aniline, 1-naphthol also reacts with more than one TAD group. A reliable analysis could be done using 2-naphthol, as it a forms a 1:1 adduct with TAD (ESI Figure S5). To determine the TAD content, three different batches of urazole potassium gels were oxidized using $\mathrm{HNO}_{3}$.

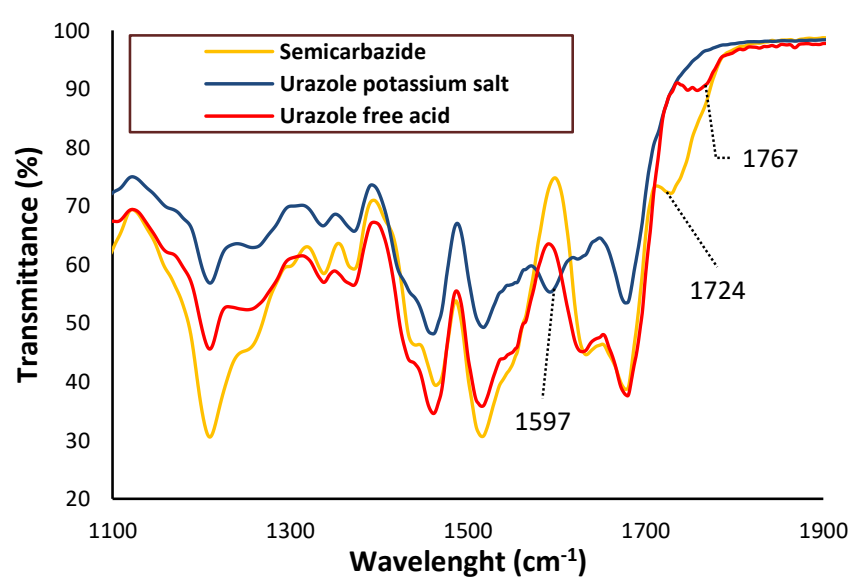

Figure 2. FT-IR spectrum of urazole potassium gel, urazole free acid gel and semicarbazide gel.

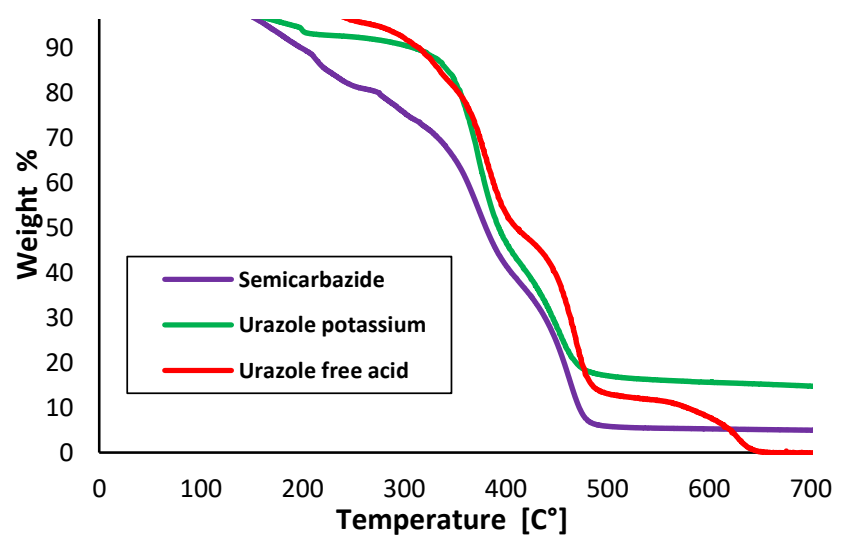

Figure 3. Thermogravimetric analysis of semicarbazide gel, urazole potassium hydrogel and urazole free acid gel.

Quantification was done by using 2-naphtol as the target molecule. ${ }^{1} \mathrm{H}-\mathrm{NMR}$ results showed that an average of $0.71 \mathrm{mmol}$ active TAD per gram of gel (Table 1). It should be noted that some active TADs decomposed over time, without reacting with furan or 2-naphtol, which resulted in a smaller value than the actual value. Theoretically, a maximum of $1.65 \mathrm{mmol}$ of TAD may be present if equimolar ethyl carbazate and triisocyanate are used at the beginning of the synthesis.

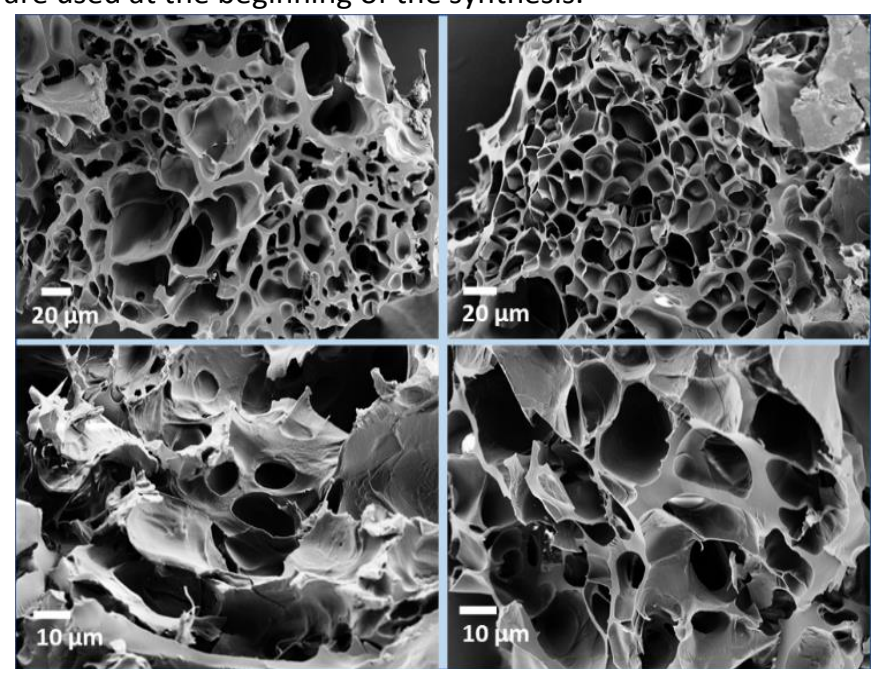

Figure 4. Scanning electron microscop image of freeze dried urazole potassium hydrogels. 

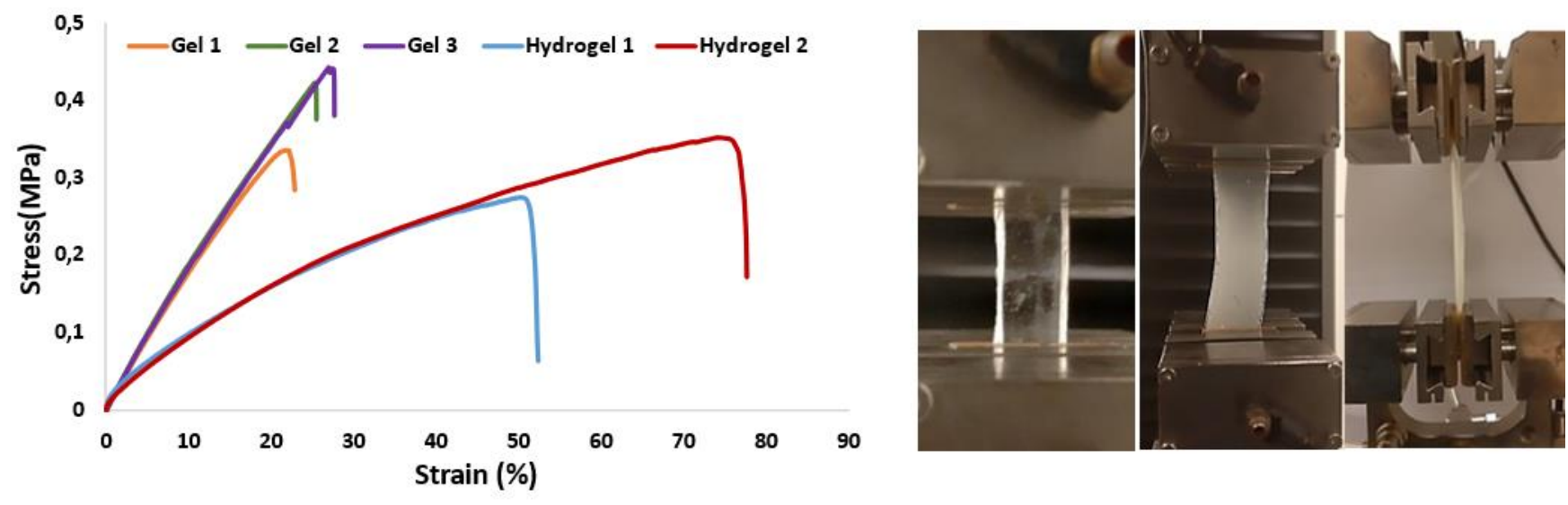

\begin{tabular}{ccc}
\hline Material & Elastic Modulus (MPa) & Ultimate Stress (MPa) \\
\hline Gel & $2,15 \pm 0,04$ & $0,499 \pm 0,047$ \\
Hydrogel & $0,91 \pm 0,01$ & $0,311 \pm 0,040$ \\
\hline
\end{tabular}

Figure 5. Mechanical analysis of urazole potassium hydrogel and semicarbazide gels.

Table 1. Triazolinedione contents of gels via 2-naphtol loss

\begin{tabular}{cccccc} 
& \multicolumn{2}{c}{ 2-Naphthol Loss } & & \multicolumn{2}{c}{ Active TAD $^{\mathbf{b}}$} \\
Batch & $(\%)$ & $\mathrm{mg}$ & $\mathrm{mmol}$ & $\mathrm{mmol}$ & $\mathrm{mg}$ \\
Gel 1 & 26,9 & 5,38 & 0,037 & 0,74 & 76,3 \\
\hline Gel 2 & 23,6 & 4,74 & 0,033 & 0,66 & 67,9 \\
\hline Gel 3 & 25,8 & 5,18 & 0,036 & 0,72 & 74,2 \\
Average & 25,4 & 5,10 & 0,035 & 0,71 & 72,7
\end{tabular}

[a] Determined by ${ }^{1} \mathrm{H}-\mathrm{NMR}$ for $50 \mathrm{mg}$ gel, [b] calculated for 1 gram of material.

The swelling ratio of the hydrogel was $87 \%$. Scanning electron microscopy showed that the hydrogel has a porous structure like a sponge, with pore sizes between 12 and $30 \mu \mathrm{m}$ (Fig. 4). The porous structure and pore sizes of the gels can be tuned by changing the curing conditions, such as temperature, initiator amount, or stoichiometric ratio of isocyanate and ethyl carbazate. Generally, a porous structure is a desired property of hydrogels, as it increases the surface area and aids diffusion of molecules, such as drugs and biologics.

We analyzed the thermal stability of the hydrogel using thermogravimetric analysis (TGA). The TGA analysis showed that the semicarbazide gel was thermally the least stable (Fig. 3). It should be noted that in the urazole cyclization step, the high temperature probably helped unreacted isocyanate (i.e., isocyanate remaining in the gel network) to react to form extra bonds, resulting in higher thermal stability for urazole gels. The urazole free acid gel was slightly more stable than its potassium salt version below $300^{\circ} \mathrm{C}$. This might be due to the hydrogen bonding capability of the urazole group when urazole is in free acid form. Under the same conditions, the urazole-potassium salt has a residual mass of $14.85 \%$ of its weight after heating to $700^{\circ} \mathrm{C}$, whereas semicarbazide $5.01 \%$ and free acid has only $0.05 \%$. The potassium mass contribution to the material is heoretically $12.90 \%$ that explains high residual mass for urazole potassium gel.

Figure 5 shows the tensile test results for the semicarbazide gel and urazole-potassium hydrogel. The test was conducted when the hydrogel was in a swollen state. As can be seen, semicarbazide has a higher elastic modulus than the hydrogel, and it is also more brittle than the hydrogel. However, the hydrogel shows hyperplastic behavior, which is common for hydrogels. The results of each group are consistent with each other, which is a sign of good reproducibility and consistency of gel synthesis. The mechanical properties of the samples, such as Young's modulus and ultimate stress and strain at break, are presented (Fig. 5). The Young's modulus of the gel and hydrogel was $2.15 \mathrm{MPa}$ and $0.91 \mathrm{MPa}$, respectively. For some application such as cartilage replacement, choice of hydrogels are limited because the modulus of most hydrogels is in the order of 0.1 MPa. Moreover, the gel and hydrogel ultimate stress is 0.499 $\mathrm{MPa}$ and $0.311 \mathrm{MPa}$, respectively and their strain at break is 25 $\%$ and $62.5 \%$, respectively. It means that the hydrogel strain at break is almost 2.5 times the strain at break for the gel while its ultimate stress is $40 \%$ less than the gel. It means the although the hydrogel became ductile compared to gel but there is no drastic decrease in its strength.

Figure 6A shows the results of the WST-1 cell viability assay of HSF cells treated with solutions containing $0.032 \mathrm{mg} / \mathrm{ml}$ and $0.016 \mathrm{mg} / \mathrm{ml}$ of urazole for $2,6,24,48$, and 72 hours. As shown in Figure $5 \mathrm{~A}$, the hydrogel did not affect the viability of the cells at lower concentrations but reduced cell viability in a dose- and time-dependent manner. Figure 5B shows both while light (left) and confocal microscopy images (right) of the cells on the hydrogel containing $0.032 \mathrm{mg} / \mathrm{ml}$ of urazole after $72 \mathrm{~h}$. As can be seen, there was no noticeable change in their morphology. Figure $6 \mathrm{C}$ shows a comparison of while light images of the proliferation of the cells treated with the extraction solution at 

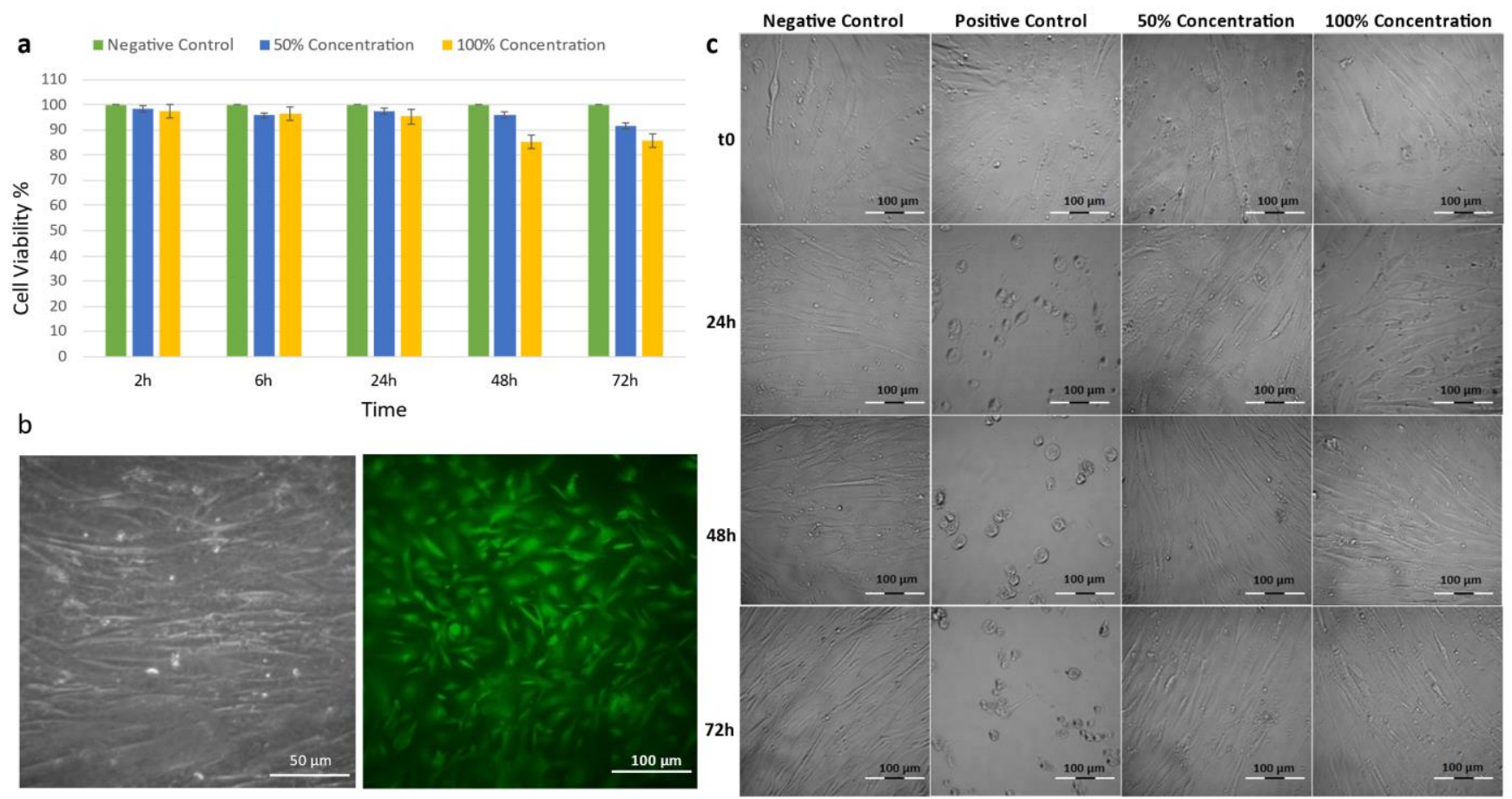

Figure 6 (a) Cell viability results at increasing extraction solution concentrations and increasing time. All tests were repeated in four independent incubations for each experiment, and each experiment was repeated three times, (b) Light (left) and confocal (right) microscope images HSF cells on hydrogel surface on day 3 and (c) White light images of cells before the urazole treatment, and on each day after the urazole treatment

two concentrations for 72 hours. Consistent with the viability results, the hydrogel did not exhibit a significant toxic or affect cell viability and attachment. Overall, the data in the present study suggest that the prepared hydrogel can be considered a biocompatible material and that it should be further evaluated. We observed that urazole changing its potassium ions with ion in the medium over time. Possible mechanism is shown in scheme 2. It is expected that urazole's unique ionic character selectively binds to higher valent ions and releases its potassium ions. Ion-chromatography analyses shown that urazole potassium gel can remove $\mathrm{Ca}^{+2}$ and $\mathrm{Mg}^{+2}$ ions completely, $\mathrm{Na}^{+}$ partially from the tap water in exchange with $\mathrm{K}^{+}$ions (Fig. 7). This shows that urazole can be used to reduce water hardness. We also tested effect of urazole on water hardness with commercially available water hardness test kits. The results showed that urazole potassium gel $(1 \% \mathrm{w} / \mathrm{w})$, reduces the water

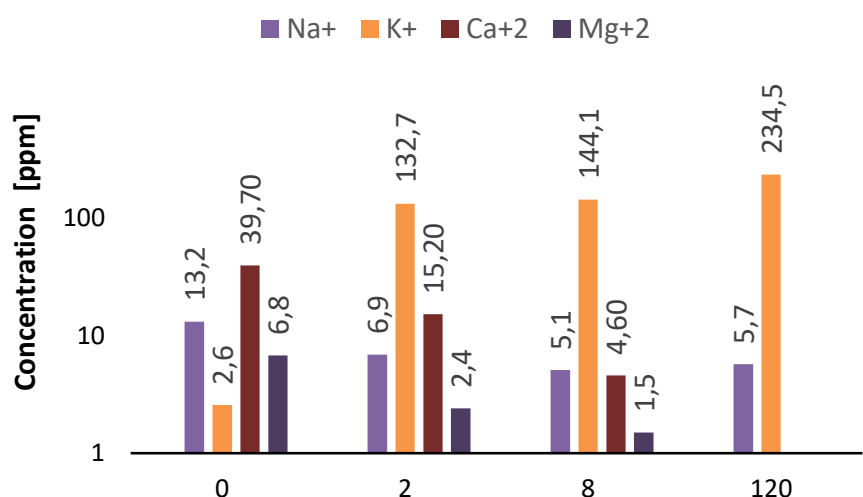

Figure 7. Ion-chromatography analysis of tap water that was treated with urazole potassium gel for 2,8 and 120 hours. hardness of tap water from $3.6^{\circ} \mathrm{dH}$ to $1.3^{\circ} \mathrm{dH}$ when gel was kept in water for 12 hours. When gels were kept for 36 hours, the water hardness reduced to $0.1^{\circ} \mathrm{dH}$ for the same amount of the gels.

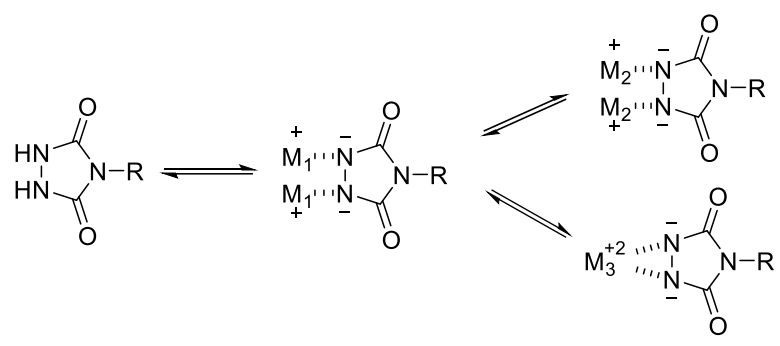

Scheme 2. Possible ion-exchange mechanism of urazole group.

\section{Conclusions}

In conclusion, we demonstrated an easy way to fabricate a urazole containing hydrogel. It showed superior mechanical properties and good cell viability indicating its biocompatibility, and potential biomedical and in ion-exchange applications in addition to being able to synthesize in large scales.

\section{Acknowledgements}

The authors would like to thank Sabanci University Fens Fellowship Program and also to Tubitak 1512 Start-up funding program. 


\section{Notes and references}

1 S. Cascone, G. Lamberti, Int. J. Pharm., 2020, 573 ,118803,

O. Wichterle, D. Lim, Nature, 1960, 185, 117

J. Kopecek, J. Polym. Sci. Pol. Chem, 2009, 47, 22, 5929-5946

4 E. Calo, V. V. Khutoryanskiy, Eur. Polym. J., 2015, 65, 252-267

5 J. Chen, H. Park, K. Park, J. Biomed. Mater. Res., 1999, 44, 1, 53-62

6 K. R. Kamath, K. Park, Adv. Drug. Deliv. Rev., 1993, 11, 59-84

7 G. D. Nicodemus, S. J. Bryant, Tissue Eng. Part B Rev.,2008, 14, 2, 149-165

8 P. S. Baran, C. A. Guerrero, E. J. Corey, Org. Lett., 2003, 11, 1999-2001

9 H. Ban, J. Gavrilyuk, C. F. Barbas, J. Am. Chem. Soc., 2010, 132,1523-1525

10 S. Billiet, K. D. Bruycker, F. Driessen, H. Goossens, V. V. Speybroeck, J. M. Winne, F. E. Du Prez, Nat. Chem., 2014, 6, 815-821

11 A. Naik, J. Alzeer, T. Triemer, A. Bujalska, N. W. Luedtke, Angew. Chem. Int. Ed., 2017, 36, 10990-10993

12 S. B. Hanay, J. O'Dwyer, S. D. Kimmins, F. C. S. de Oliveira, M. G. Haugh, F. J. O'Brien, S. A. Cryan, A. Heise, ACS Macro Lett., 2018, 7, 944-949

13 H. A. Houck, E. Blasco, F. E. Du Prez, C. Barner-Kowollik, J. Am. Chem. Soc., 2019, 141, 12329-12337

14 P. Mondal, G. Jana, P. K. Behera, P. K. Chattaraj, N. K. Singha, Macromolecules, 2020, 53, 8313-8323

15 A. G. Choghamarani, Z. Chenani, S. Mallakpour, Synth. Commun., 2009, 39, 4264-4270

16 M. A. Zolfigol, M. H. Zebarjaidan, G. Chehardoli, S. E. Mallakpour, M. Shamsipur, Tetrahedron, 2001, 57, 1627-1629

17 A. Rahimi, D. Habibi, A. Rostami, M. A. Zolfigol, S. E. Mallakpour, Tetrahedron Lett., 2018, 59, 383-387

18 S. Sato, K. Hatano, M. Tsushima, H. Nakamura, Chem. Commun., 2018, 54, 5871-5874

19 J. F. W. Keana, A. P. Guzikowski, D. D. Ward, C. Morat, F. L. Van Nice, J. Org. Chem., 1983, 48, 2654-2660

20 W. Laure, K. De Bruycker, P. Espeel, D. Fournier, P. Woisel, F. E. Du Prez, J. Lyskawa, Langmuir, 2018, 34, 2397-2402

21 P. G. Gordon, L. F. Audrieth, J. Org. Chem., 1955, 20, 603-605

22 S. Ohashi, K. Leong, K. Matyjaszewski, G. B. Butler, J. Org. Chem., 1980, 45, 3467-3471.

23 M. J. Bausch, B. David, P. Dobrowolski, C. Guadalupe-Fasano, R. Gostowski, D. Selmarten, V. Prasad, A. Vaughn, L. H. Wang, J. Org. Chem., 1991, 56, 5643-5651

24 S. E. Mallakpour, B. Karami-Dezcho, B. Sheikholeslami, Polym. Int., 1999,45, 98-102

25 R. L. Sowerby, Urazole compositions useful as additives for functional fluids, U.S. Patent No. -0877637. Washington, DC: U.S. Patent and Trademark Office.

26 D. R. Adams, A. F. Barnes, F. Cassidy, M. Thompson, J. Chem. Soc., Perkin Trans., 1984, 1, 2061-2067

27 V.M. Kolb, J.P. Dworkin, S.L. Miller, J. Mol. Evol., 1994, 38,549557

28 R. Yang, W. Mu, Q. Chen, Food and Analytical Methods, 2019 12, 1805-1812

29 S. B. Hanay, B. Ritzen, D. Brougham, A. A. Dias, A. Heise, Macromol. Biosci., 2017, 17, 1700016

30 S. B. Hanay, Chemrxiv, 2020, ChemRxiv. Cambridge: This content is a preprint and has not been peer-reviewed. 